Physical Sciences | Valeriia Reveko

\section{Setting new horizons in electroplating of zinc die castings}

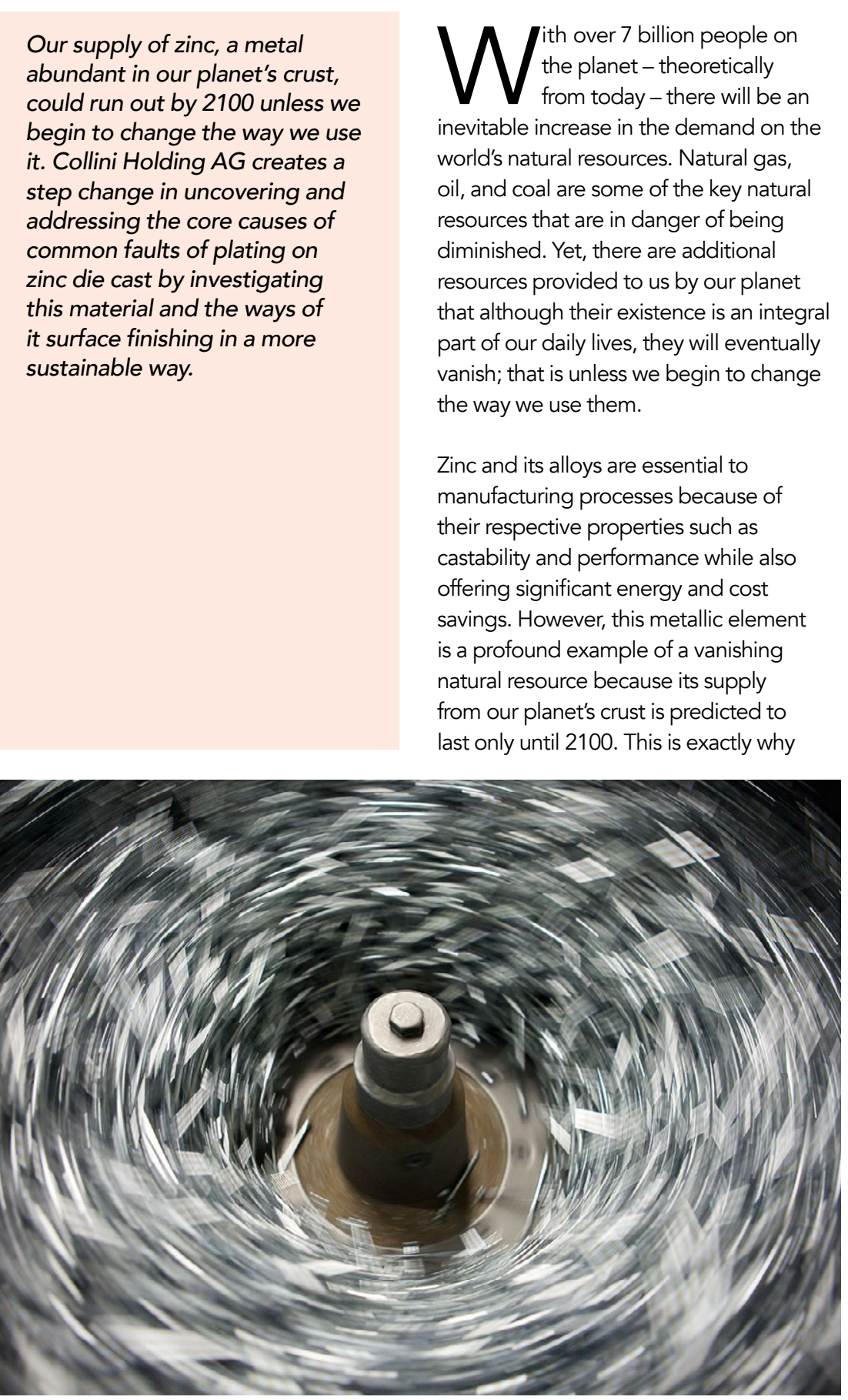

Collini Holding AG, the leading group of companies in coating metals and plastics in Europe, has been investigating and developing surface solutions to render zinc alloys more sustainable and over 120 . industrial sufface treatment company creating surfaces for fittings, electrical and automotive industry machine plant and building construction, and also for medicine and various consumer goods The company has thirteen production sites in Austria, Germany, Italy, Russia, Mexico and Switzerland that specialise in a wide range of surface technologies including electroplating, hot-dip galvanizing, anodizing and organic coating.

\section{ZINC DIE CASTING}

From toy cars that children play with to the metal parts used in actual cars, there is a huge variety of consumer parts made using the die casting process. In fact, die been around for more than 180 years and was initially invented in order to develop press involves heating mally, his they become molten and consequently pressed between steel moulds until they cool down and solidifiy in the required shape. One of the most popular alloys to use in the die casting process is zinc alloys because they are easier to cast and solidifif at a lower temperature in comparison to alternatives such as aluminium, therefore the die casting process is cheaper and more efficient.

Zinc is a hard, ductile, self-lubricating material that has high thermal conductivi and dimensional stability. However, susceptible to corrosion in acidic and/or strong alkaline environments. Therefore certain elements, like aluminium or with superior properties. Although, adding those dissimilar elements the way to corrosion, a process of metal deterioration In this way, electroplating coatings are a necessity in order to change surface properties: reduce meta cations from a solution with the help of electric current, and hence form a protective metallic coating. Furthermore, and disregarding the long usage of electroplating as the surface treatment for , zinc die casting persistently generates several challenges for plating, especially when it comes to decorative use (Reveko and Moller, 2018). Consequently, there are avaniety of challenges associated with zinc die casting that has recently become the primary research of the Austrian surface
treatment company Collini Holding AG in

SPECIAL ASPECTS OF

ELECTRODEPOSITION ON ZINC DIE CASTINGS

Zinc cie casting part in cross section: difference
in structure between the surface and the bulk

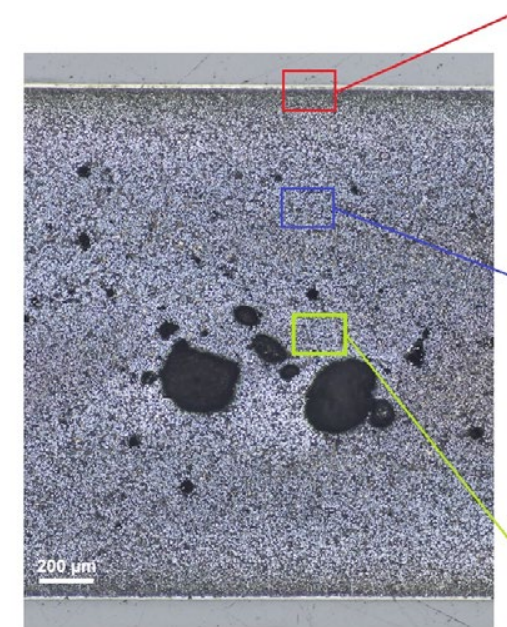

By 2100, it is anticipated the supply of most metals will run out.

conjunction with the Technical University in the completion of a series of studies by Collini scientist Valeriia Reveko.

ZINC PLATING COLOUR CHANGE Valeriia Reveko, a PhD candidate in the Department of Mechanical Engineering, DTU, has published several peer-reviewed research studies that highlight the distinct challenges that are associated with the (a) thorough morphological and

compositional tests and analyses to verify the performance and safety of zinc galvanic coatings on zinc die-cast iten improve the plating quality For instance, and as noted in Reveko, Lampert, Winther

and Moller (2018), one of the most common issues with zinc coating over zinc die-cast components involves a distinct 作 surface of the electroplated zinc coatings. In this study, Reveko and co-workers suggest that aluminium from the substrates will gradually diffuse throug the coating and will propel the manifestation of these blue areas as a result of oxidation under the influence of contaminatis. Furthermore, and perhaps which zinc plating occurs - from alkaline or acidic solution-directly inflences the rate of aluminium diffusion: alkaline zinc demonstrates higher rates of diffusion
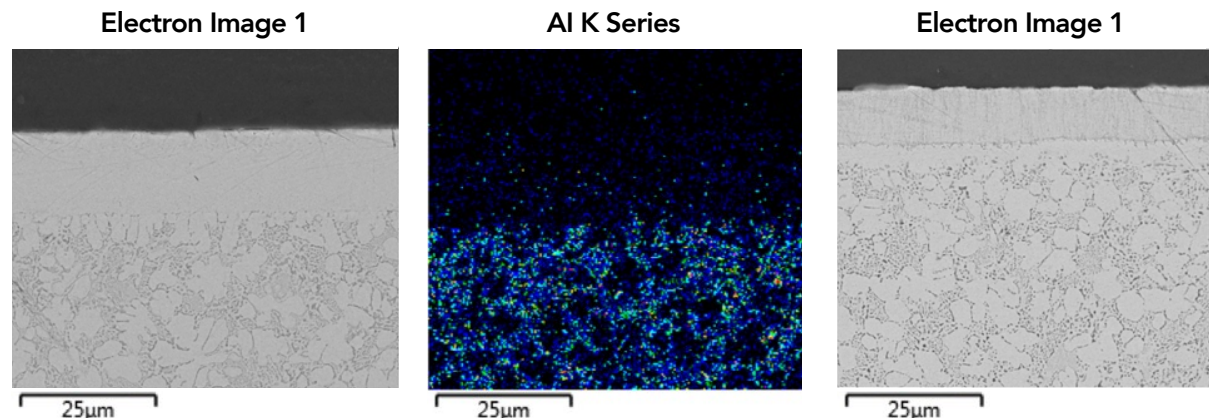

$25 \mu \mathrm{m}$

Scanning electron microscope images with Enerergy
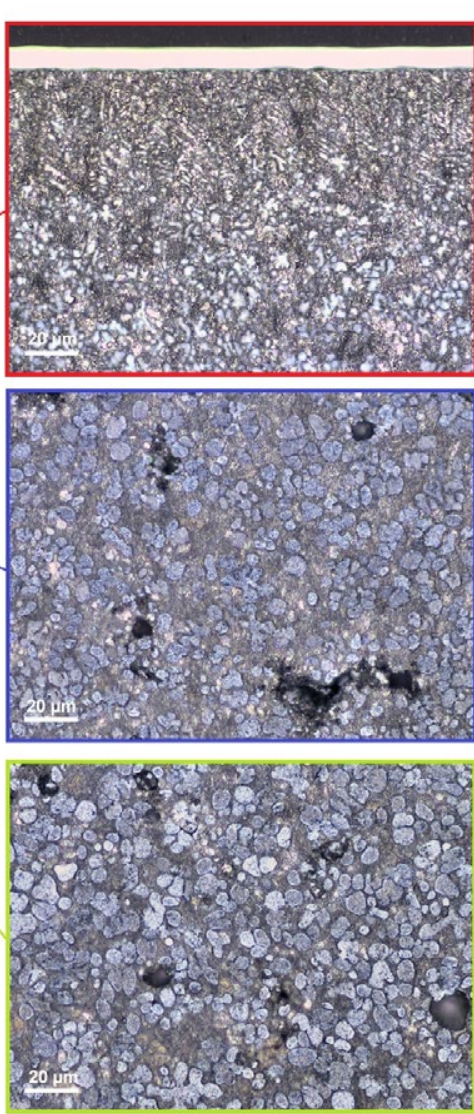

morphology. Hence, and as suggested (a) a double-layered zinc coating in which the inner layer is ind the outer layer

INACCURATE ANALYSIS

OF CHROMIUM-PASSIVATED

ZINC SURFACES

(I) corlosion environmental and safety requirements.

However some recent research studies reported the presence of hexavalent chromium in the surface passivation layers.

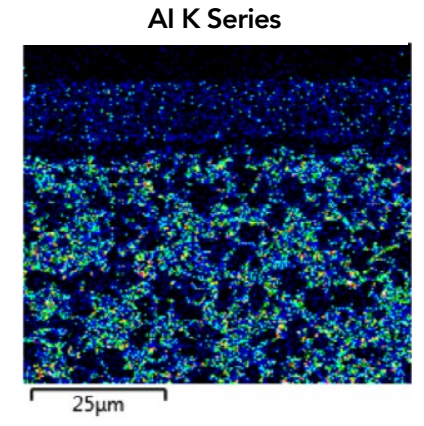


The Registration, Evaluation, Authorisation and Restriction of Chemicals (REACH) has they are carinogenic In addition, $4 \%$ of peole in Europe and 5\% in America are allergic to chromium, and hexavalent $\mathrm{Cr}$ is much more likely to cause a skin reaction such as dermatitis than the trivalent on

In general, colourimetric

1,5-diphenylcarbazide (DPC)-based spot test is one of the principal methods used to identify hexavalent chromium on various metallic and leather surfaces. However, and as noted in Reveko, Lampert, Din, Thyssen and Møller (2018)

Research in Collini intends to reveal and address the causes of common plating faults and support sustainable use of materials.

passivated zinc surfaces can actually be misleading. X-ray photoelectron spectroscopy (XPS) measurements performed in this research study did not verify the presence of hexavalent chromium previously identified on such surfaces by DPC. The study suggests that unintended oxidation of the DPC indicator in reaction with the substances present

on the surface because of atmospheric positive results. The importance of this study is not limited to the impeccable level of quality control needed in the Europe metal industry, but also because these false-positive results can unavoidably result in the prescription of erroneous treatment to patients with contact dermatitis.

ZINC RESPONSIBLE USAGE CYCLE

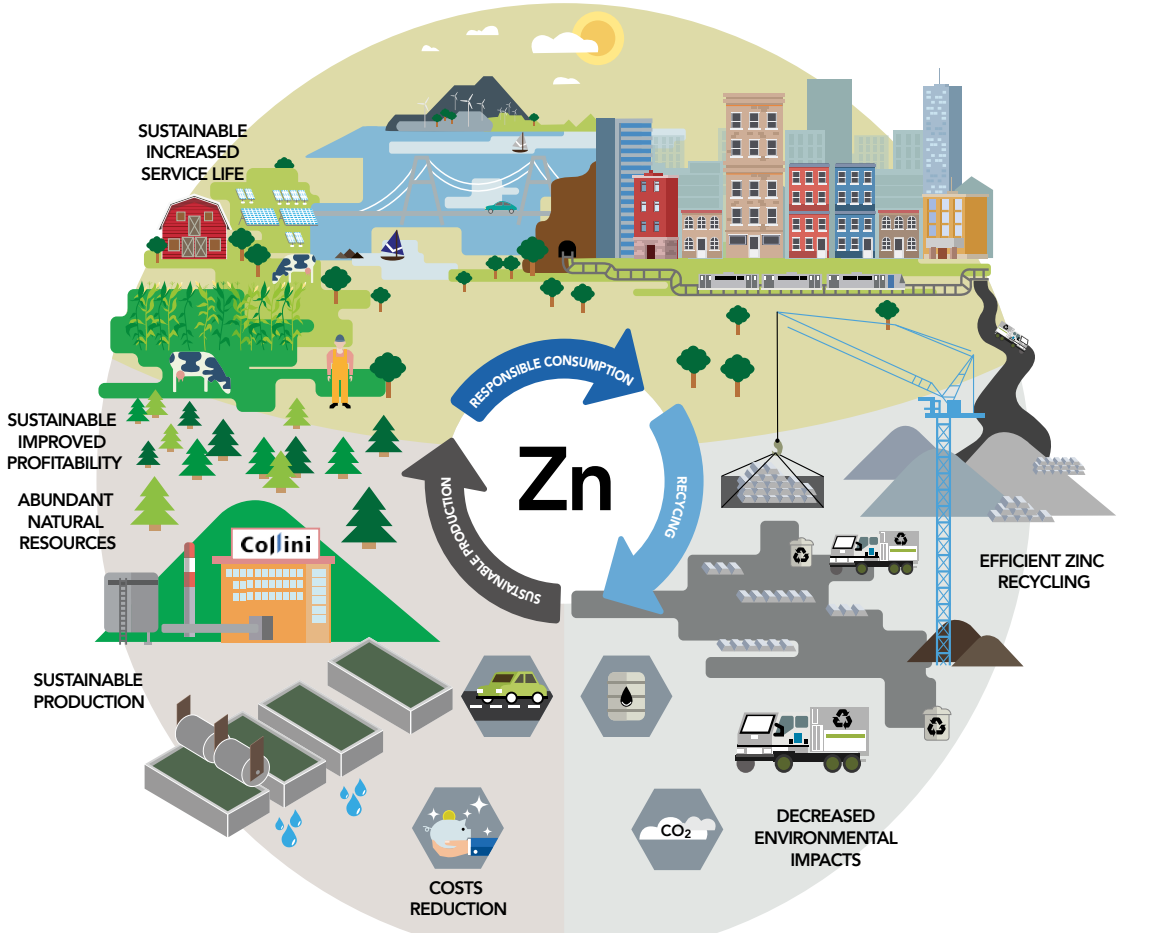

SUSTAINABLE SOLUTIONS

This research would be remiss if it did not consider the present-day ecological 列 layers of different metals that are tricky to recycle. This is because separating metals such as chromium and nickel - metals that are traditionally used to coat zinc metal alloys - is a process with increased energy demands. Therefore, researchers have shifted their focus on coating zinc alloys with zinc coatings because this process reduces the overall number of metals used, thus rendering the recycling process easier. This is exactly why Collini has turned its attention towards improve approaches of the surface treatment of zinc die-cast parts. The usage of recycled zinc is an energetically favouring process

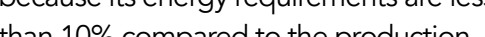
than $10 \%$ compared to the production presented in this article is directly connected to the increasing industrial need for recyclable zinc comp

\section{CONCLUSIONS}

This research conducted by Collini intends to identify and evaluate the core causes of common plating faults while supporting Reveko's study provides greater insight Ret ths study provides greater insight while at the same time of zinc die castings evaluate the hidden challenges of zincplated and zinc die-casted components, ple

\section{Behind the Research}

Valeriia Reveko

w: collini.eu

\section{Research Objectives}

$\mathrm{PhD}$ candidate Valeriia Reveko from the Austrian electroplating company Collini, has completed a series of studies looking into how to make the usage of zinc more sustainable.

\section{Detail}

Collini GmbH,

Schweizer Str. 59,

Austria

Bio

Valeriia Reveko is a Product-and Process Development engineer in Collini GmbH, Austria. She holds an MSc degree in technical electrochemistry from Kiev Polytechnic Institute and is conducting a PhD project in materials science and surface technology at the Technical University of Denmark (DTU).

Funding

The research was funded by Collini GmbH, Hohenems

Collaborators
- Professor Per Møller, Technical University of Denmark (DTU).

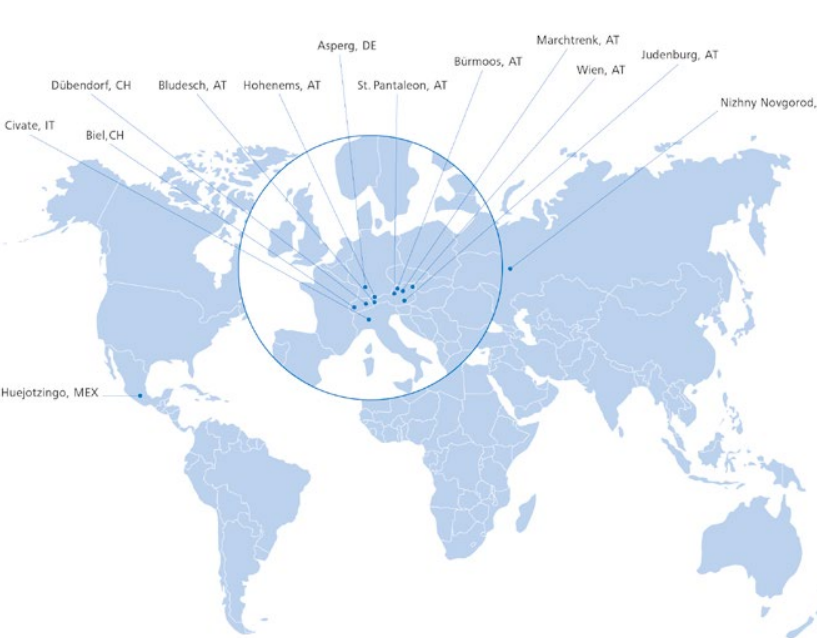

\section{References}

Valeriia Reveko and Per Møller (2018). 'Special Aspects
of Electrodeposition on Zinc Die Castings'. NASF Surface of Electrodeposition on Zinc Die Castings'. NASF Surface
Technology White Papers, 82 (8), pp. 1-9, Article Post: Technology

Valeriia Reveko, Felix Lampert, Grethe Winther and Per Moller (2018).'Change of The Decorative Properties Of Zinc-
Plated Zinc Die Castings Over Time'. International Journal of Plated Zinc Die Castings Over Time'. International Journal of Metalcasting, pp. 1-7, https://doi.org/10.1007/s40962-018

Valeriia Reveko, Felix Lampert, Rameez Ud Din, Jacob P. Thyssen, Per Møiller (2018) 'False-positive result when a diphenyl carbazide spot test is used on trivalent chromium5, pp. 315-320, doi:10.11111/cod.12955.

\section{Personal Response}

\section{Why do you think it's important to find ways}

II It is my position that in today's world, we cannot continue to use natural resources in such an exploiting given us a great deal, and the least we can do in return is to use these resources wisely. Zinc, copper, nickel, steel, aluminium, plastic - before putting those materials to the market, we must carefully consider the whole product lifecycle, aiming for sustainable solutions, and the surface impact on this.

'Applied surface intelligence' is the motto at Collini, and we all work together with the aim of using materials
more effectively.

Collini 